\title{
Porous polyethylene implant for cranioplasty and skull base reconstruction
}

\author{
James K. LiU, M.D., Oren N. GotTfried, M.D., Chad D. Cole, M.Sc., \\ William R. Dougherty, M.D., AND William T. Couldwell, M.D., PH.D. \\ Department of Neurosurgery, University of Utah School of Medicine, Salt Lake City, Utah; and \\ Department of Surgery, Penn State College of Medicine, Hershey, Pennsylvania
}

\begin{abstract}
Object. Cranial reconstruction after skull base surgery is important for restoration of function and cosmesis. The authors describe their experience with the Medpor porous polyethylene implant for cosmetic cranioplasty and reconstruction after skull base surgery.

Methods. Medpor, a biocompatible implant, is flexible and can be contoured to facilitate surgical reconstruction of small to medium $(<8 \mathrm{~cm})$ convexity or cranial base defects resulting from a variety of skull base approaches. This method provides similar cosmetic results to standard alloplast cranioplasty while decreasing operating time. The porous nature of the material allows ingrowth of soft tissue and bone to increase implant strength and decrease the risk of infection. This material can also be used safely in reconstruction of the cranium and skull base adjacent to the paranasal sinuses.

Conclusions. The authors have used the Medpor porous polyethylene implant in 611 standard cranial and skull base procedures and have achieved excellent cosmetic results and no implant-related complications.
\end{abstract}

\section{KEY WORDS - cranioplasty - cranial base reconstruction porous polyethylene implant $\bullet$ biomaterial}

Reconstruction of cranial base and craniofacial defects is an important goal after skull base surgery. ${ }^{9}$ Although biocompatibility characteristics are optimal in autogenous grafts, the risk of donor site morbidity, difficulty with graft contouring, and prolonged operating time limit their use. The desire for immediate functional and aesthetic reconstruction after skull base surgery has led to increased use of alloplastic materials, including silicone, porous hydroxyapatite, titanium mesh, and methyl methacrylate. . $^{1,4,7,11,13,20}$

The Medpor porous polyethylene Flexblock implant (Porex Surgical, Inc., Newnan, GA) is a biocompatible material that is composed of high-density polyethylene microspheres that are sintered to create a framework of interconnected pores approximately $150 \mu \mathrm{m}$ in diameter. ${ }^{2,3,22}$ Its porous character allows for rapid fibrovascular and soft tissue ingrowth and eventual incorporation of bone, which strengthens the implant as well as decreases the risk of infection. . $, 8,10,12,18,21$ The Medpor Flexblock implant is flexible and can easily be contoured to accommodate a variety of skull defects. It has long been used as a standard reference material for biocompatibility testing and has been used in cranioplasty, craniofacial repair, and skull base reconstruction. . $3,6,7,9,16-19,22$ We have found the Medpor implant to be a useful material for cranioplasty and reconstruction after skull base surgery. We describe

Abbreviation used in this paper: $\mathrm{CT}=$ computerized tomography. our surgical technique in which the Medpor Flexblock implant is used and report our experience with it in 598 patients.

\section{CLINICAL MATERIAL AND METHODS}

\section{Patient Population}

The surgical records and medical charts of all patients who underwent a vascular, skull base, or epilepsy procedure performed by the senior author (W.T.C.) between January 1996 and December 2003 were reviewed for the use of the Medpor porous polyethylene implants for cranioplasty and skull base reconstruction. A total of 598 patients underwent 611 procedures in which Medpor was used. Thirteen patients underwent bilateral procedures or surgeries via two different approaches, and Medpor was therefore used at separate locations in these patients. The surgical procedure described later was applied only to cranial defects smaller than $8 \mathrm{~cm}$.

\section{Surgical Implant Procedure}

The Medpor implant is manufactured in a variety of sheet thicknesses and sizes. This material is available as smooth sheets of various thicknesses or as sheets with conical projections (Flexblock implant) to add bulk if desired (Fig. 1). It may be fashioned with Mayo scissors or a scalpel to cover the cranial defect. An outline of the cra- 


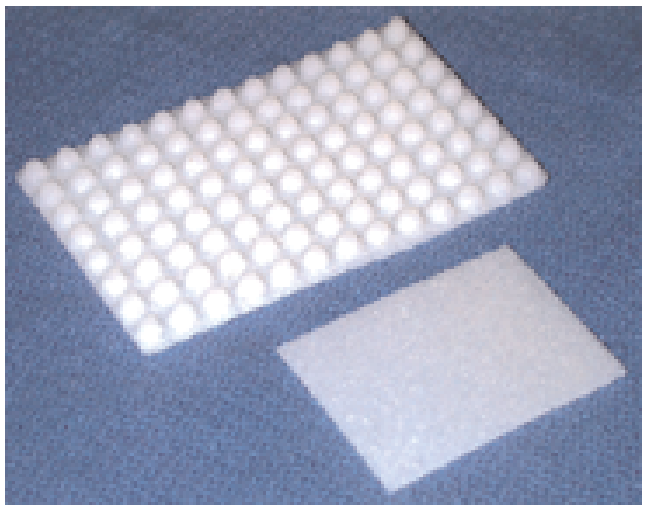

Fig. 1. Photograph showing sheets of the Medpor porous polyethylene implant. This material is available in a variety of sheet thicknesses and sizes. The Flexblock implant (upper left) has a smooth exterior surface with conical projections on the undersurface that enable the implant to be flexed to the desired contour. Alternatively, a smooth, thin sheet of Medpor (lower right) can also be used.

nial defect is made on a paper template and then transferred to the surface of the implant to obtain an accurate and aesthetic fit. An allowance is made for molding and edge approximation by cutting the implant slightly larger than the template. Once the desired shape of the implant is obtained, its edges are feathered with a No. 10 blade scalpel to obtain a smooth contour to the surrounding bone, thereby approximating the edge of the implant to the craniotomy edge with no irregularity. Alternatively, a highspeed drill may be used to create a shelf at the edge of the craniotomy to seat the edge of the implant into the surrounding bone. Fixation is performed by placing titanium screws directly through the implant into the bone. With thicker implants that are used to cover larger cranial defects, screws can be placed directly into the implant, which is fastened to the bone edge with titanium miniplates and screws (Fig. 2).

\section{RESULTS}

The Medpor porous polyethylene implant was used in 611 procedures, predominantly skull base or vascular surgeries that required cranioplasty or reconstruction of the cranial base. As shown in Table 1, the implant was most commonly used after a craniotomy for aneurysm clip occlusion $(59 \%)$, followed by resection of skull base tumors $(34 \%)$. Most of the skull base tumors were meningiomas $(70 \%)$, followed by vestibular schwannomas $(10 \%)$. As illustrated in Figs. 3 and 4, Medpor was also used for microvascular decompression (5\%) and in epilepsy surgery $(2 \%)$. The most common skull base procedure used was the frontotemporal approach (pterional, transcavernous, or orbitozygomatic) in 458 patients $(75 \%)$, followed by the retrosigmoid approach in $100(16 \%)$, the subtemporal approach in $42(7 \%)$, and the craniofacial approach in $11(2 \%)$.

The mean follow-up period was 4 years (range 1 month-8 years). There were no postoperative infections and no wound breakdowns. On follow-up review, all patients had satisfactory cosmetic outcomes as judged by the
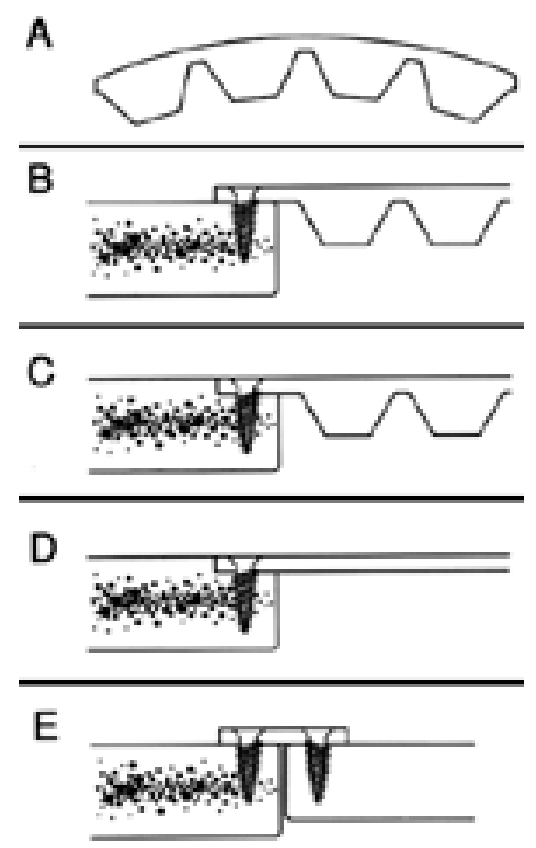

Fig. 2. Drawings demonstrating various options for Medpor implant fixation. A: The cones on the undersurface of the Flexblock implant enable it to be flexed to the desired contour. B: After the implant is cut to the desired shape, it is fastened in place with titanium screws. To facilitate an acceptable cosmetic result, the cones at the edge of the implant are shaved to allow the piece to be lapped to the surrounding bone edge. C: Alternatively, a shelf may be created at the edge of the cranial defect to seat the edge of the implant into the surrounding bone. D: A thin, smooth sheet of Medpor can also be used instead of the Flexblock implant. E: For thicker implants that are used to cover larger cranial defects, screws can be placed directly into the implant, which is fastened to the bone edge with titanium miniplates and screws. (Reprinted in modified form with permission from Couldwell WT, Chen TC, Weiss $\mathrm{MH}$, et al: Cranioplasty with the Medpor porous polyethylene Flexblock implant. Technical note. J Neurosurg 81:483-486, 1994.)

patient and the senior author. No patient required further surgery to correct cosmetic problems caused by their initial operation.

\section{DISCUSSION}

Implantable biomaterials play an important role in cranioplasty and reconstruction after skull base surgery. For the surgical closure, well-vascularized tissue should be used for obliteration of dead space and for skull base coverage. Next, attempts should be made to restore function and to optimize the cosmetic result. Although autogenous

TABLE 1

Indications for the use of Medpor in 611 craniotomies

\begin{tabular}{lc}
\hline \multicolumn{1}{c}{ Type of Op } & No. of Cases $(\%)$ \\
\hline aneurysm & $359(59)$ \\
skull base tumor & $207(34)$ \\
microvascular decompression & $30(5)$ \\
epilepsy & $15(2)$ \\
\hline
\end{tabular}



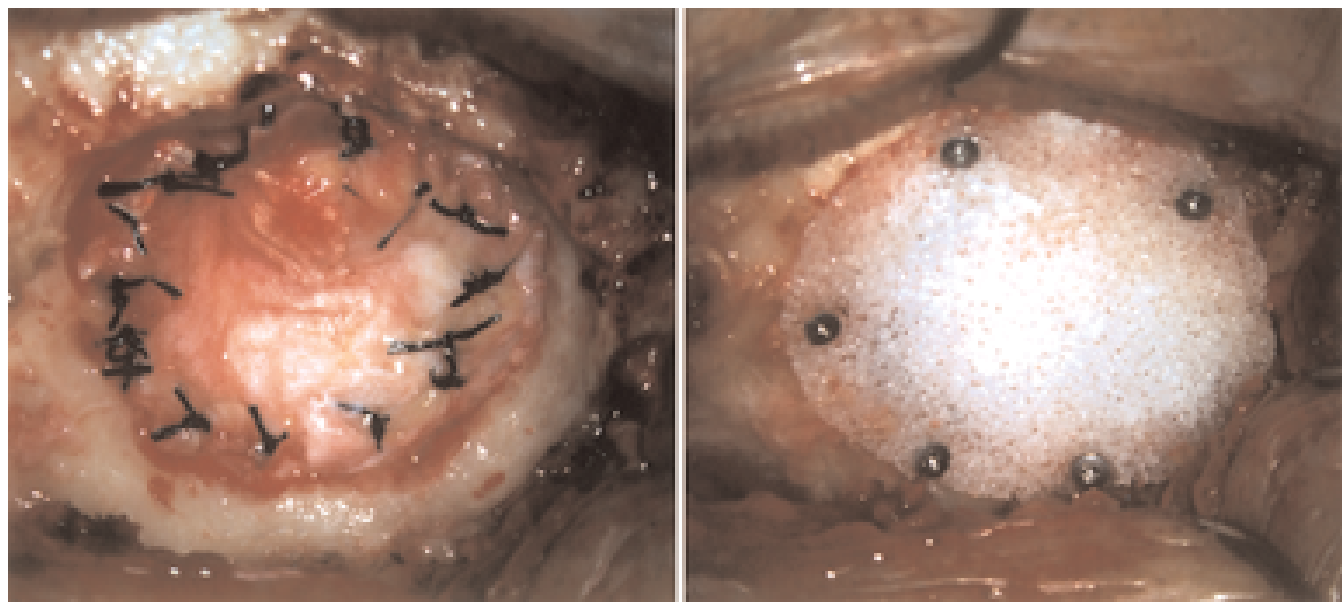

Fig. 3. Intraoperative photographs showing Medpor cranioplasty performed after a retrosigmoid approach for microvascular decompression to treat trigeminal neuralgia. The retromastoid defect (left) has been covered with a small 1.5 mm-thick sheet of Medpor that has been fastened to the surrounding bone with 4-mm titanium screws (right).

grafts are optimally biocompatible, the risks of donor site complications and increased operating time have limited their use.

Methyl methacrylate, although commonly used in combination with titanium or wire mesh, ${ }^{11,15}$ may be associated with potential complications that include local tissue damage caused by the heat released during the exothermic reaction, release of a toxic monomer that has been associated with local and systemic reactions, and a prohibitively high rate of infection when used adjacent to contaminated paranasal sinuses. ${ }^{3}$ Titanium mesh is highly inert, nontoxic, nonantigenic, noncarcinogenic, and easily shaped. The tissue biocompatibility of titanium is reflected in the low risk of infection, provided that the surrounding soft tissue is adequate to permit tissue integration. ${ }^{7,17}$ Nevertheless, titanium produces image artifacts on postoperative CT and magnetic resonance imaging studies.

The use of a Medpor porous polyethylene implant is a quick and effective method for immediate cranioplasty and reconstruction after skull base surgery. This biomaterial is readily available in various shapes and sizes, is eas-

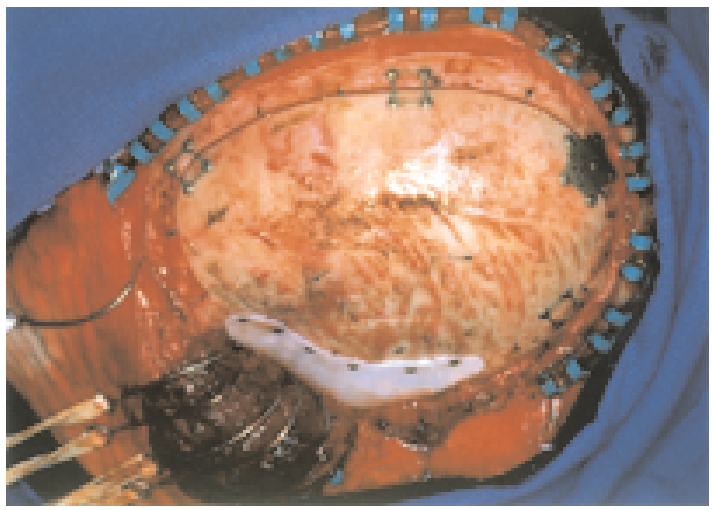

Fig. 4. Intraoperative photograph showing the Medpor Flexblock implant covering the temporal craniectomy defect after a craniotomy for epilepsy. The implant was lapped to the surrounding bone edge and fastened with titanium miniscrews. ily contoured to cover a variety of cranial defects, and is well tolerated by patients. Polyethylene is a highly inert material that exhibits minimal foreign body reaction and has been proven stable over many years of use in humans. ${ }^{2,17,22}$ It is also radiolucent on CT scans and magnetic resonance images, enabling improved visualization on postoperative neuroimages (Fig. 5). ${ }^{3}$

The porous architecture enables rapid ingrowth of blood vessels and soft tissue within 3 to 4 weeks, promoting wound healing and forming a stable interface that anchors the implant (Fig. 6). This ingrowth of vascularized soft tissue resulted in normal mucosal covering of the implant when Medpor was placed adjacent to the contaminated maxillary sinus in an orbital blow-out fracture model in rabbits. ${ }^{4}$ Over longer periods, bone eventually incorporates at the implant-bone interface, providing implant stability. Some investigators have suggested that the vascular ingrowth may protect the implant from infection..$^{12}$ In a report by Romano, et al., ${ }^{16}$ there were no infectious complications when the Medpor implant was used

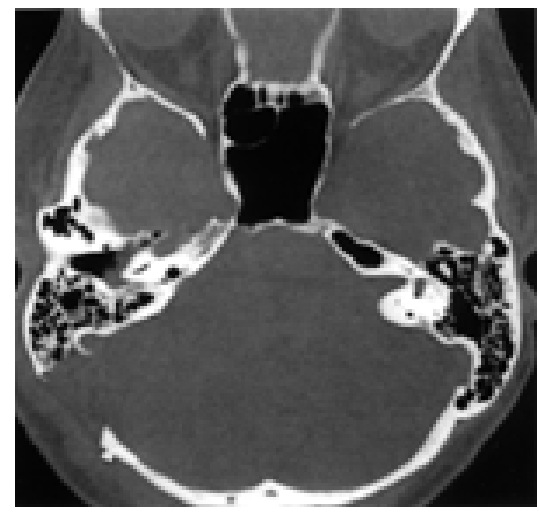

Fig. 5. Postoperative CT scan obtained after a right retrosigmoid approach was performed for resection of a vestibular schwannoma followed by Medpor cranioplasty. The Medpor implant is radiolucent and produces no imaging artifact. Note the titanium miniscrews used to fasten the implant to the surrounding bone. 


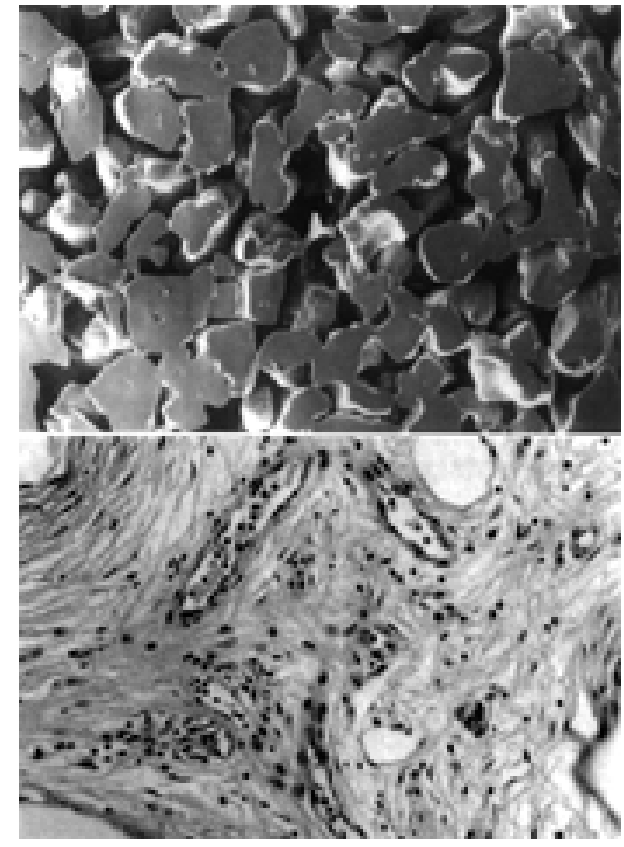

Fig. 6. Upper: Scanning electron micrograph demonstrating the porous nature of the implant. Original magnification $\times 23$. Lower: Histological section showing ingrowth of fibrovascular host tissue into the Medpor implant after a 3-month period in a human craniofacial application. $\mathrm{H} \& \mathrm{E}$, original magnification $\times$ 75. (Reprinted with permission from Couldwell WT, Chen TC, Weiss MH, et al: J Neurosurg 81:483-486, 1994.)

in 140 cases of open facial fractures. In our large experience with 611 surgical procedures, there were no postoperative infections or wound breakdowns. All patients achieved a satisfactory cosmetic outcome.

In our series, the pterional approach for aneurysm clip occlusion or tumor resection was the most frequent skull base operation performed. We routinely use the Medpor implant to cover the temporal defect that is created by this approach. The implant is fashioned and contoured to cover the defect and is fixed to the superior edge of the bone defect with two titanium screws. Because the implant is placed deep beneath the temporalis muscle, added bulk is provided under the muscle, which compensates for temporalis muscle atrophy and minimizes the risk of temporal hollowing (Fig. 7). The resultant ingrowth of vascularized host tissue also provides long-term augmentation and stabilization of the temporal defect. A preformed pterional Medpor implant is now commercially available from Porex Surgical, Inc. It has been used routinely by other surgeons after pterional craniotomy and has shown excellent biomechanical properties. ${ }^{14}$

We have also used the Medpor implant for skull base reconstruction in defects that were exposed to adjacent paranasal sinuses. In most of these cases, the implant was used for orbital or anterior skull base reconstruction after a craniofacial resection of a malignant tumor of the anterior skull base and paranasal sinuses. Because the implant allows rapid ingrowth of vascularized host tissue, there is less risk of an infection. ${ }^{3,7}$ Eventually, there is complete mucosal overgrowth on the implant, even after postoperative radiation therapy.

For larger cranial defects that may require sharp-contoured reconstructions, the implant may need additional molding, which can be easily accomplished by placing it in a hot sterile saline bath for several minutes. The heat causes the Medpor implant to relax slightly, enabling it to be bent to the desired shape. After cooling, the implant will retain its altered contour. For defects larger than $8 \mathrm{~cm}$, which require increased strength, we recommend customized implants that can be created with the aid of high-resolution, three-dimensionally reconstructed CT scans (Fig. 8).
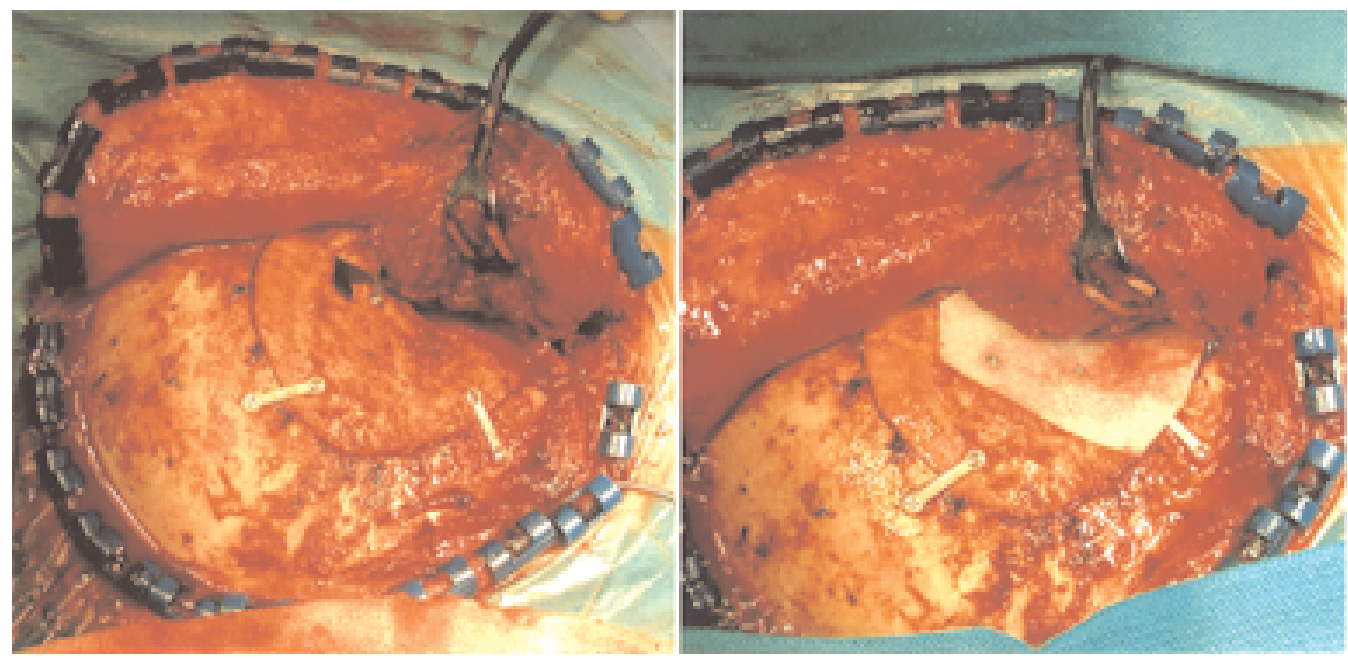

Fig. 7. Intraoperative photograph showing cranioplasty accomplished using the Medpor implant after a pterional craniotomy. Left: After a pterional craniotomy, there is a temporal defect. Right: The implant is fashioned and contoured to cover the defect and is fixed to the superior edge of the bone defect with two titanium screws. Because the implant is placed deep beneath the temporalis muscle, added bulk is provided under the muscle, which compensates for temporalis muscle atrophy and minimizes the risk of temporal hollowing. 

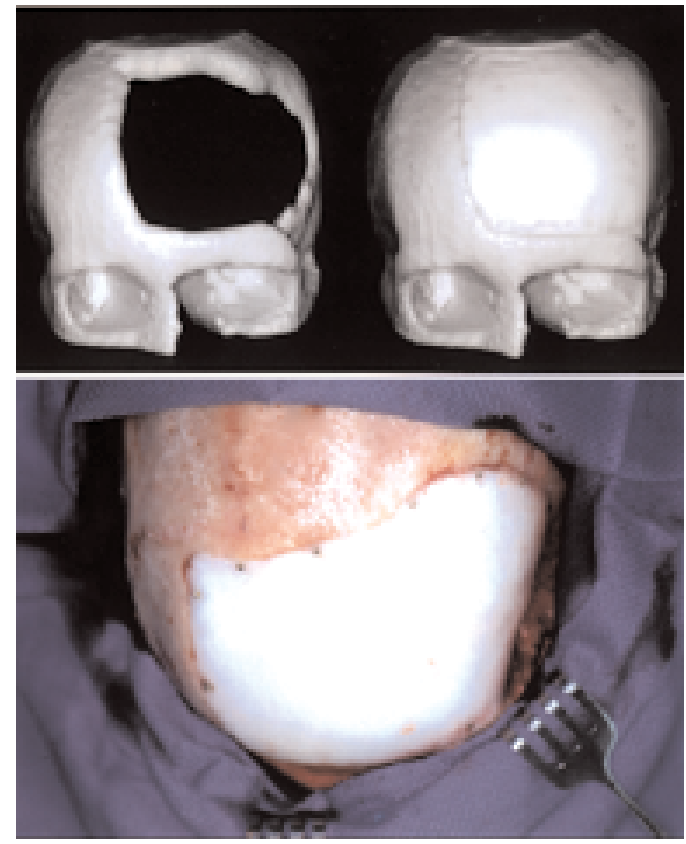

Fig. 8. Upper: Three-dimensional CT reconstruction demonstrating a large cranial defect in the left frontal bone. This reconstructed CT scan was used to design a customized cranial implant. Lower: Intraoperative photograph showing a customized porous polyethylene implant that was created with the aid of the reconstructed CT scan.

In this series, the Medpor implant has been used for small and medium cranial defects $(<8 \mathrm{~cm})$ in a variety of skull base approaches. Our experience indicates that the Medpor porous polyethylene implant offers a safe and cosmetically viable option for cranioplasty and reconstruction after skull base surgery. It is faster to perform than methyl methacrylate cranioplasty and, in our experience, has been associated with a lower rate of infection.

\section{Disclaimer}

We have no financial interest in and have not entered into a consultation agreement with the manufacturer of the materials discussed in this paper.

\section{References}

1. Blake GB, MacFarlane MR, Hinton JW: Titanium in reconstructive surgery of the skull and face. Br J Plast Surg 43: 528-535, 1990

2. Couldwell WT, Chen TC, Weiss MH, et al: Cranioplasty with the Medpor porous polyethylene Flexblock implant. Technical note. J Neurosurg 81:483-486, 1994

3. Couldwell WT, Stillerman CB, Dougherty W: Reconstruction of the skull base and cranium adjacent to sinuses with porous polyethylene implant: preliminary report. Skull Base Surg 7: 57-63, 1997
4. Dougherty W, Wellisz T: The natural history of alloplastic implants in orbital floor reconstruction: an animal model. J Craniofac Surg 5:26-33, 1994

5. Gosain AK, Persing JA: Biomaterials in the face: benefits and risks. J Craniofac Surg 10:404-414, 1999

6. Homsy CA: Bio-compatibility in selection of materials for implantation. J Biomed Mater Res 4:341-356, 1970

7. Janecka IP: New reconstructive technologies in skull base surgery: role of titanium mesh and porous polyethylene. Arch Otolaryngol Head Neck Surg 126:396-401, 2000

8. Klawitter JJ, Bagwell JG, Weinstein AM, et al: An evaluation of bone growth into porous high density polyethylene. J Biomed Mater Res 10:311-323, 1976

9. Liu JK, Niazi Z, Couldwell WT: Reconstruction of the skull base after tumor resection: an overview of methods. Neurosurg Focus 12 (5):Article 9, 2002

10. Maas CS, Merwin GE, Wilson J, et al: Comparison of biomaterials for facial bone augmentation. Arch Otolaryngol Head Neck Surg 116:551-556, 1990

11. Malis LI: Titanium mesh and acrylic cranioplasty. Neurosurgery 25:351-355, 1989

12. Merritt K, Shafer JW, Brown SA: Implant site infection rates with porous and dense materials. J Biomed Mater Res 13: 101-108, 1979

13. Ousterhout DK, Baker S, Zlotolow I: Methylmethacrylate onlay implants in the treatment of forehead deformities secondary to craniosynostosis. J Maxillofac Surg 8:228-233, 1980

14. Park HK, Dujovny M, Diaz FG, et al: Biomechanical properties of high-density polyethylene for pterional prosthesis. Neurol Res 24:671-676, 2002

15. Rish BL, Dillon JD, Meirowsky AM, et al: Cranioplasty: a review of 1030 cases of penetrating head injury. Neurosurgery 4:381-385, 1979

16. Romano JJ, Iliff NT, Manson PN: Use of Medpor porous polyethylene implants in 140 patients with facial fractures. J Craniofac Surg 4:142-147, 1993

17. Rubin JP, Yaremchuk MJ: Complications and toxicities of implantable biomaterials used in facial reconstructive and aesthetic surgery: a comprehensive review of the literature. Plast Reconstr Surg 100:1336-1353, 1997

18. Rubin LR: Polyethylene as a bone and cartilage substitute: a 32year retrospective, in Rubin LR (ed): Biomaterials in Reconstructive Surgery. St Louis: CV Mosby, 1983, pp 474-492

19. Rubin PA, Bilyk JR, Shore JW: Orbital reconstruction using porous polyethylene sheets. Ophthalmology 101:1697-1708, 1994

20. Schulz RC: Reconstruction of facial deformities with alloplastic materials. Ann Plast Surg 7:434-446, 1981

21. Spector M, Flemming WR, Kreutner A: Bone growth into porous high-density polyethylene. J Biomed Mater Res 10: 595-603, 1976

22. Wellisz T, Dougherty W, Gross J: Craniofacial applications for the Medpor porous polyethylene Flexblock implant. J Craniofac Surg 3:101-107, 1992

Manuscript received January 15, 2004.

Accepted in final form February 10, 2004.

Address reprint requests to: William T. Couldwell, M.D., Ph.D., Department of Neurosurgery, University of Utah, 30 North 1900 East, Suite 3B409, Salt Lake City, Utah 84132. email: william.couldwell@hsc.utah.edu. 